\title{
Glucose-galactose malabsorption
}

INSERM

\section{Source}

INSERM. (1999). Orphanet: an online rare disease and orphan drug data base. Glucosegalactose malabsorption. ORPHA:35710

Glucose-galactose malabsorption (GGM) is a very rare, potentially lethal, genetic metabolic disease characterized by impaired glucose-galactose absorption resulting in severe watery diarrhea and dehydration with onset inthe neonatal period. 